\title{
ROS KEETON: 'I FEEL VERY STRONGLY THAT AS A PROFESSION WE SHOULD LOOK AFTER OUR OWN'
}

\author{
Professor Ros Keeton is Honorary Treasurer and Trustee for the BDA Benevolent Fund, visiting Professor at \\ the Faculty of Health at Birmingham City University and a Fellow at the University of Worcester. Ros was a \\ partner at Keetons Dental Practice in Kinver with her husband for just over 30 years and is an experienced \\ NHS Chief Executive. News Editor Kate Quinlan spoke to Ros about her work for the BDA Benevolent Fund.
}

\section{Why did you choose dentistry?}

I'm fundamentally interested in patient care and that drives everything I do, focussing relentlessly on high performance medicine and patient experience. When I was at school the thing that I think attracted me was that as a dentist you have the opportunity to diagnose your patient, and then to treat them and take responsibility for their care over a long time, potentially a lifetime. Therefore, you really see the impact of what you're doing as an individual with that person (depending on where you work in dentistry). That's what attracted me, that holistic view of someone over time. Some of those things that were initially interesting to me about dentistry are still guiding principles in the work that I do now.

\section{How did you first get involved} with the BDA Benevolent Fund?

It was a classic situation. A colleague said to me we're looking for a new trustee, I don't suppose you've ever thought about helping the Ben Fund? I looked into it and thought that it would be a really interesting thing to do.

A lot of dentists know the Ben Fund exists, but I suppose until there is a particular reason for you look into it, it is just one of those things that you recognise as something the profession does for itself. It's all about dentists helping other dentists.

When you hear or become involved in a story then it starts to become real and interesting. People start to understand what we're trying to do and why and how it's all about us helping our own profession - which is the link

\section{'Dentistry} has done me a huge favour - so this is about me giving back to dentistry...' to me. I'm a really weird dentist in career terms but dentistry has been really good to me - it gave me a background and training that has set me up very well and allowed me to have loads of opportunities. Dentists that I have worked with and trained with over the years are still great friends of mine so I think dentistry has done me a huge favour - so this is about me giving back to dentistry.

\section{What are your duties as Honorary} Treasurer and Trustee of the Fund? As a trustee your duty is to help set the strategy, to scrutinise the charity to make sure that it is being run properly, has good governance and so on, and safeguarding the charity to make sure that it's doing what it was really set up to do. All trustees have those responsibilities. As Treasurer my focus is primarily about money. I look at how we're spending our money on our beneficiaries and how we're fundraising to bring money in. I've got an overarching responsibility for the finance for every aspect: with day to day management and making sure that on a month by month basis financial matters are in hand.

\section{Does promoting} and working for the Benevolent Fund take up a large portion of your time?

It's really variable. One of the things about the Fund is that there are bits of work that you can choose to do when it's convenient for you to do it, but there are bits that are very time critical. For instance, if a beneficiary contacts us and says they are in crisis, for example somebody who has no food or money to buy food, or someone who is about to become homeless, we set ourselves the standard that we will assess that individual rapidly. If individuals need emergency help we decide within 48 hours. I think that's the right thing to do, particularly in those sorts of situations. But it does mean that there are times when we have got to be quite fleet of foot and sort things out really quickly, so those sorts of jobs you can't put off. Our primary purpose is to help our beneficiaries. We don't want to see dentists homeless and we don't want to see dentists unable to feed themselves and their families.

I think a lot of the profession would think "do dentists really become homeless, do they really not have enough money to buy food?' Well yes they do. Luckily not hundreds but we do get dentists who ring up in that situation.

The role is a balance between being really responsive but also recognising that we are all unpaid volunteers and we're fitting it around everything else that we do.

As an officer of the trust I check my emails very regularly. The phones here are manned during office hours or there is remote access so we can pick up messages. If we know someone isn't going to be in the office we would arrange to pick up any messages just in case there's someone who needs urgent help.

\section{Prior to your involvement with the} Fund, had you known a beneficiary? At the time I came onto the charity I didn't think I knew anyone who had been helped by the Fund, but now I know that I did. 
I am quite well known now as a Ben Fund person and I've had private conversations where people have come up to me, often thanking me for what I'm doing, and saying 'you probably didn't realise this but five years ago...' or 'my partner was...' things like that which you would never have realised. Few dentists have the - would you call it courage? - to actually admit that the Ben Fund has helped them.

I tell a story quite a lot about going to see a beneficiary in my own patch, I was just going for that initial visit to meet them and work through their paperwork. That's always a difficult visit for the beneficiary because they've got this person turning up from the Ben Fund, they know that they want help, but it's always quite difficult when you knock at their door. So I knocked on this chap's door and said (big smile on my face, looking kind and approachable, because we are kind and approachable), 'Hi, I'm Ros, I'm from the Ben Fund', and he welcomed me into his hallway and he said 'yes it's all right, I know who you are'. I said 'do you?' And I looked at him and thought I really don't recognise him at all, and wondered where I met him, and smiled benignly. He said, 'yes I know you, Ros, because I saw you give a presentation about the Ben Fund about 18 months ago at the Hilton Hotel and I put £20 in your bucket.' He then said something that I've heard other beneficiaries say; he said, 'I never thought when you told me those stories about people you've helped and when I gave you the $£ 20$ that you would knock at my door to help me'.

\section{Roughly how many people contact the Ben Fund?}

We receive enquires from round 30-40 new individuals or families a year in addition to the people we support on a regular basis. Most look at our website to see what support we offer before sending in an application, so the vast majority of people who contact us we end up helping, largely because they know they meet our criteria. This is why we have updated the website and our publicity materials lately - they are so important.

When we talk publicly about what we're doing we say: 'if you know somebody who needs our help, point them in the right direction', because we are still concerned that there are people out there who don't come to us because they don't realise that they can, or they come to us so late that by the time they get to us they're in such a bad state.

The youngest dentist we helped last year was 24 and the oldest 89 . We also support very recently graduated dentists who have been dental students in hardship. Sometimes a dental student who qualifies, and I'm talking about a dental student who perhaps sleeps in the library, who hasn't got anywhere to live, for them now paying their ARF is a large amount of money - where do they get it from?

If you looked at the data years ago, the beneficiaries were very different. Often they were widows of dentists, dentists who had died early and so on. These days the trend is for most beneficiaries to be dentists between 30-40 years old. They come from all over the UK, every branch of dentistry: consultants, professors, GDPs, DF1s, all sorts.

\section{What are the main reasons people contact the Fund?}

Illness plays a big part, often acute and chronic illness - either physically sick or mentally unwell. They might have had cancer or a stroke, something that is a life-changing condition. Another big issue is that $50 \%$ of our applicants in the last 2-3 years have been involved in GDC procedures so we've started working more closely with the GDC. The problem is when someone is in fitness to practise procedures and they have stopped working, they will not be able to work sometimes for up to two years. That has a huge impact on people both financially and emotionally. The GDC have been very receptive to working with us to find out ways to make these cases go through quicker.

\section{Is assessing the applications to the Fund a difficult task?}

Yes, it is difficult because everyone is different and often they are in very complex situations. What you want to do is respond to that individual but also try to treat them fairly compared with everybody else. We have people of all ages, from individuals who are single with no family or friends able to help out to one beneficiary with six young children. Someone who lives in London will have different housing costs to someone who lives in Scotland so we have to consider all factors. Each person who contacts the Fund is asked to fill out an application (this is available on the website). Everyone then gets a visit where we build up a picture and ask for further details. All the information is reported to the executive committee, who assess the applications in great detail.

Everyone who gets a grant we review after an agreed period; the maximum is a year. Sometimes someone comes to us with a oneoff request for help - for example they might say, "if you could pay my ARF and give me a small grant, I'm starting a new job next month and can manage from then on'. We have some long-term beneficiaries on the margins of society, on means-tested benefits, that we review annually and still visit annually, partly because that helps us understand what's happening to them and partly because for some of them we're an important person in their lives and they look forward to our visit.

I've got one person who I take out for lunch once a year; I don't suppose he ever goes out for lunch. We talk in private first about his situation and how he's managing, and then I take him to a local café. He always has the same, a croque monsieur and a cafetière of coffee and an Eccles cake afterwards and we talk about dentistry. He enjoys that.

Our primary focus is to help try and get beneficiaries back to work, ideally dentistry, but if not then some other paid occupation. If we can't get them back into employment of some form then we want to try and get them to be financially independent. We have quite a good success rate $-60 \%$ of the people we helped last year returned to work or became financially independent. We might pay for someone to do a training course or support them in whatever way we can to help them towards financial independence. We want to get them to a point where they have at the least a basic quality of life.

\section{Does the Fund have to work hard to invite donations and encourage fundraisers?}

We have to manage our money very carefully and we spend all of our 
donations on helping dentists. At the moment there are just enough donations coming in but it is very tight. The more we receive the more we can spend on extending our support. We are talking about possibly extending our services, particularly to dentists who are under stress. The people who come to us have already got a serious problem, they've hit the bottom. What we are interested in doing is helping people before they reach this stage to prevent them ever getting there. We couldn't afford to do that at the moment but we'd like to think about doing it in the future; that would necessitate bringing in more money.

The Fund has superb support from LDCs and BDA branches; more than $50 \%$ of our donations come from LDCs and every pound raised through fundraising goes directly to the beneficiary.

We've got some fantastic supporters who very regularly do fundraising activities and some of them send us money on an annual basis - a big thank you to all of them.
How do you balance your role with the Fund with your other responsibilities?

I suppose you balance it because you want to. I'm passionate about what we're doing. I feel very strongly that as a profession we should look after our own. I have been doing some work on the history of the Fund. It was set up by Samuel Rymer and others including Sir John Tomes in 1883. There are some minutes in the BDA Museum about their first meetings and they were saying at that time and I still think it's entirely true - that a marker of a proper profession is that it cares about its own. They felt very passionately that they had to start looking after the widows and orphans of dentists. That's how it started. They put together the initial idea of having a Fund and all contributing to it. That legacy is what we still have today.

\section{Is there anything else you would} like to say to $B D J$ readers?

I just want to say again that we are approachable and friendly. It is a huge barrier for people to come to us, to admit that they need help, which is why we get people that have gone so far down that road. I have had a call from someone who said I actually haven't got any food, any money or credit and it's Friday, can you help? We always hope to be able to say yes.

We are always looking for new passionate volunteers to be trustees or to help us in other ways. Please give us a ring or send us an email if that person is you. We would love to have a chat with you.

The BDA Benevolent Fund will be telling people about their work at this month's British Dental Conference and Exhibition in Manchester. To encourage people to 'have fun with the Benevolent Fund' you will be able to have a wacky photograph taken in a photo booth in return for a small donation. www.bdabenevolentfund.org.uk 